\title{
A novel low-cost and environment-friendly cathode with large channels and high structure stability for potassium-ion storage
}

Weike Wang ${ }^{1,3 \dagger}$, Bifa Ji $^{1,2 \dagger}$, Wenjiao Yao ${ }^{1 *}$, Xinyuan Zhang ${ }^{5}$, Yongping Zheng ${ }^{1}$, Xiaolong Zhou ${ }^{1}$,
Pinit Kidkhunthod ${ }^{6}$, Haiyan $\mathrm{He}^{1,3}$ and Yongbing Tang

\begin{abstract}
Potassium-ion batteries (KIBs) are promising candidates for large-scale energy storage due to the abundance of potassium and its chemical similarity to lithium. Nevertheless, the performances of KIBs are still unsatisfactory for practical applications, mainly hindered by the lack of suitable cathode materials. Herein, combining the strong inductive effect of sulphate and the feasible preparation of $\mathrm{Fe}^{2+}$-containing compounds in oxalate system, a compound with novel architecture, $\mathrm{K}_{4} \mathrm{Fe}_{3}\left(\mathrm{C}_{2} \mathrm{O}_{4}\right)_{3}\left(\mathrm{SO}_{4}\right)_{2}$, has been identified as a lowcost and environmentally friendly cathode for stable potassium-ion storage. Its unique crystal structure possesses an unprecedented two-dimensional framework of triple layers, with $3.379 \AA$ interlayer distance and large intralayer rings in the size of $4.576 \times 6.846 \AA$. According to first-principles simulations, such a configuration is favorable for reversible $\mathrm{K}$ ion migration with a very low volume change of $6.4 \%$. Synchrotron $\mathrm{X}$-ray absorption spectra and $\mathrm{X}$-ray diffraction characterizations at different charging/discharging states and electrochemical performances based on its half and full cells further verify its excellent reversibility and structural stability. Although its performance needs to be improved via further composition tuning with multi-valent transition metals, doping, structural optimization, etc., this study clearly presents a stable structural model for $\mathrm{K}$-ion cathodes with merits of low cost and environmental friendliness.
\end{abstract}

Keywords: potassium-ion cathode, Fe-based polyanionic compound, low cost, environment friendly

\section{INTRODUCTION}

Due to the limited $\mathrm{Li}$ resources and their geographic unevenness, lithium-ion batteries (LIBs) can hardly satisfy large-scale energy storage fields for renewable energy sources such as solar, wind, etc., where the cost and environmental influence should be considered even in the sacrifice of energy densities to a certain extent [1-4]. Among potential alternatives, potassium-ion batteries (KIBs) are attracting intense academic and technological interest due to the abundance of potassium and its chemical similarity to lithium over sodium [5-7]. For KIB technologies, several families have been explored as anode materials with high capacity and long cyclability, including intercalation-type, conversion-type, and alloying type materials [8-16]. In comparison, the development of ideal cathode materials, such as Prussian blue analogues (PBAs), oxides, polyanions, and organics [17-22] are sluggish. For instance, despite of enormous investigations on PBAs, of which the three-dimensional (3D) open framework structure is promising for $\mathrm{K}$-ion storage, the preparation of defect-free and water-free PBAs is difficult, which deteriorates the electrochemical performance of PBAs in terms of kinetics, Coulombic efficiency (CE), and cycling life [23-26].

Recently, polyanionic compounds have gradually at-

\footnotetext{
${ }^{1}$ Functional Thin Films Research Center, Shenzhen Institutes of Advanced Technology, Chinese Academy of Sciences, Shenzhen 518055, China

${ }^{2}$ University of Chinese Academy of Sciences, Beijing 100049, China

${ }^{3}$ Nano Science and Technology Institute, University of Science and Technology of China, Suzhou 215123, China

${ }^{4}$ Key Laboratory of Advanced Materials Processing \& Mold, Ministry of Education, Zhengzhou University, Zhengzhou 450002, China

${ }^{5}$ Tianjin Key Laboratory of Functional Crystal Materials, Institute of Functional Crystals, Tianjin University of Technology, Tianjin 300384, China

${ }^{6}$ Synchrotron Light Research Institute, 111 University Avenue, Muang District, Nakhon Ratchasima, 30000, Thailand

${ }^{\dagger}$ These authors contributed equally to this paper.

* Corresponding authors (emails: wj.yao@siat.ac.cn (Yao W); tangyb@siat.ac.cn (Tang Y))
} 
tracted more attention owing to their favorable working potentials, rigid structural frameworks for $\mathrm{K}$ ion movement and high stability against organic solvents. Especially, polyanions based on iron are more competitive than others, thanks to its large abundance and environmental friendliness [27,28]. Besides, the selection of polyanionic groups is also critical to constructing a highperformance polyanionic cathode. Sulphate group $\left(\mathrm{SO}_{4}\right)^{2-}$ is known to possess the strongest inductive effect on the $\mathrm{d}$ orbitals of transition metals, contributing to high working potentials. Whereas, the sulphate system tends to generate $\mathrm{Fe}^{3+}$-containing products in the presence of even trace amount of oxygen or moisture [29,30]. Such $\mathrm{Fe}^{3+}$ containing materials are electrochemically unfavorable since the practical cathode in secondary batteries needs to provide charge-carrier ions for the whole system, and should originally be in a discharged state, i.e., $\mathrm{Fe}^{2+}$ state. Consequently, various strategies have been developed to control iron state during synthesis, for instance, applying reductive atmosphere, introducing reductive agents, etc. After evaluating the reductive behavior of several candidates, we found oxalate group $\left(\mathrm{C}_{2} \mathrm{O}_{4}\right)^{2-}$ has excellent capability to form $\mathrm{Fe}^{2+}$-containing compounds $[31,32]$. Therefore, combining the merits of sulphate and oxalate groups is promising to construct low cost and high-performance polyanionic cathodes for K-ion storage.

Following above guidelines, we performed tentative exploration in the mixed sulphate-oxalate systems, resulting in a new iron-based polyanionic compound, $\mathrm{K}_{4} \mathrm{Fe}_{3}\left(\mathrm{C}_{2} \mathrm{O}_{4}\right)_{3}\left(\mathrm{SO}_{4}\right)_{2}$ (KFOS). Interestingly, its unique crystal structure contains triple octahedral $\mathrm{FeO}_{6}$ layers bridged by lateral sulphate and longitudinal oxalate, with $\mathrm{K}$ ions located at inter- and intra-layer interstices. To the best of our knowledge, such a triple-layered framework as a $\mathrm{K}$-ion host has never been reported before. Our first principle calculations suggest its configuration is excellent for reversible $\mathrm{K}$-ion migration due to the structural stability and intrinsic electronic structures, and the exploration on reaction mechanism further reveals its highly reversible $\mathrm{Fe}^{2+} / \mathrm{Fe}^{3+}$ redox reactions and structural stability. In our preliminary experiments, this polyanionic cathode showed a steady discharge capacity of $\sim 80 \mathrm{~mA} \mathrm{~h}$ $\mathrm{g}^{-1}$ at $100 \mathrm{~mA} \mathrm{~g}^{-1}$ for 500 cycles, and a K-ion full cell was successfully constructed combining this cathode with soft carbon (SC) anode, which exhibited excellent cycling stability with ignorable capacity decay over 200 cycles. Although its capacity could be improved by further composition modification, doping, and structural optimization, it provides a novel structure model for K-ion cathodes with low cost and environmental friendliness.

\section{EXPERIMENTAL SECTION}

\section{Materials}

Potassium sulfate $\left(\mathrm{K}_{2} \mathrm{SO}_{4}, 99 \%+\right)$, ferrous oxalate dihydrate $\left(\mathrm{FeC}_{2} \mathrm{O}_{4} \cdot 2 \mathrm{H}_{2} \mathrm{O}, \quad 99.5 \%\right)$, oxalate dihydrate $\left(\mathrm{H}_{2} \mathrm{C}_{2} \mathrm{O}_{4} \cdot 2 \mathrm{H}_{2} \mathrm{O}, 99 \%+\right)$ and ethanol $(99 \%+)$ were purchased from Alfa Aesar. Ketjenblack EC600JD was purchased from Lion Corporation in Japan. N-methyl-2pyrrolidone (NMP), carbon-coated Al foil (thickness, $18 \mu \mathrm{m}$ ), and Al foil (thickness, $25 \mu \mathrm{m}$ ) were purchased from Shenzhen Kejingstar Technology Co., Ltd. Propylene carbonate (PC, 99.95\%), ethylene carbonate (EC, 99.95\%), dimethyl carbonate (DMC), potassium molecular sieve and battery-grade potassium hexafluorophosphate $\left(\mathrm{KPF}_{6}, 99.5 \%\right)$ were provided by Dodochem. Potassium block (K, 99\%) and perylene-3,4,9,10-tetracarboxylic dianhydride (PTCDA) were purchased from Aladdin Reagent. Glass microfiber separators (Whatman Grade GF/D) were purchased from GE Healthcare Life Sciences. All chemicals were used directly as received.

\section{Synthesis}

KFOS crystallites were synthesized by a hydrothermal method. $\mathrm{K}_{2} \mathrm{SO}_{4}, \mathrm{FeC}_{2} \mathrm{O}_{4} \cdot 2 \mathrm{H}_{2} \mathrm{O}$, and $\mathrm{H}_{2} \mathrm{C}_{2} \mathrm{O}_{4} \cdot 2 \mathrm{H}_{2} \mathrm{O}$ were sealed in a Teflon-lined autoclave with $1.00 \mathrm{~g}$ distilled water in the molar ratio of 1:3:1 ( 1 for $1 \mathrm{mmol})$. The reaction went on under auto-generated pressure by keeping autoclaves in a $200^{\circ} \mathrm{C}$ oven for five days. The oven was then turned off until cooling down to room temperature. The resulting products were repeatedly washed with distilled water and ethanol to remove byproducts, and then dried at a vacuum environment overnight. SC was facilely synthesized by thermal polymerization of PTCDA for $4 \mathrm{~h}$ at $900^{\circ} \mathrm{C}$ with a heating rate of $10^{\circ} \mathrm{C} \mathrm{min}^{-1}$.

\section{Characterization}

Optical images of the KFOS crystallites were taken by a Leica DVM6M video microscope with ultra-depth-offield. A transparent orange KFOS crystallite in the size of $0.2 \times 0.3 \times 0.6 \mathrm{~mm}^{3}$ was chosen to collect single crystal Xray diffraction (XRD) data on a Rigaku AFC10 singlecrystal diffractometer equipped with graphite-monochromated Mo Ka radiation $(\lambda=0.71073 \AA)$. The faceindexed absorption correction was carried out based on the XPREP program. The structure was then solved by direct methods and refined using SHELX-2014 incorporated in the WinGX program. All atoms were refined anisotropically. Powder XRD patterns were performed on the finely ground pollycrystallites on a 
Rigaku diffractometer (MiniFlex600, $40 \mathrm{kV}$ and $15 \mathrm{~mA}$ ) using $\mathrm{Cu} \mathrm{Ka}$ radiation. Scans were taken over the range of $3^{\circ}-90^{\circ}$ with a $2 \theta$ step of $2^{\circ} \mathrm{min}^{-1}$. Ex-situ XRD analyses of recollected cathodes at different states, after being washed with DMC to remove electrolyte and dried overnight, were conducted on the same XRD detector at a $2 \theta$ step of $2^{\circ} \mathrm{min}^{-1}$ over the range of $10^{\circ}-40^{\circ}$. For transmission electron microscopy (TEM) characterization, a sheet from a single crystallite was prepared by an FEI Scios Focused Ion Beam/Field Emission (FE)-TEM at an accelerating voltage of $30 \mathrm{kV}$ under a selective etching process, and positioned on a $\mathrm{Cu}$ grid. The energy dispersion X-ray spectra (EDS) of TEM were conducted by a JEOL JEM3200FS FE-TEM equipped with an Oxford Instruments EDS analyzer. Thermal stability was characterized on hand-ground crystallites of about $8 \mathrm{mg}$ by simultaneous thermogravimetric and differential scanning calorimetry (TG-DSC) using a STA449F3 thermal analyzer (Netzsch, Germany), from room temperature to $800^{\circ} \mathrm{C}$ under a flow of air at a rate of $10^{\circ} \mathrm{C} \mathrm{min}{ }^{-1}$. Residual of TG-DSC analysis was checked by powder XRD as stated above.

\section{Electrochemical test}

The electrochemical performance of the KFOS/K half-cell was studied in CR2032 coin-type cells assembled in Arfilled glove box (MIKROUNA) with water and oxygen levels $\leq 0.1 \mathrm{ppm}$. To improve KFOS's conductivity, handground samples were ball-milled with Kejtenblack carbon $(3: 1 \mathrm{w} / \mathrm{w})$ for $3 \mathrm{~h}$. Subsequent powder was then ground with PVDF (85\%:15\% $w / w)$ by hand, followed by the addition of several drops of NMP solvent until forming a homogeneous slurry. The slurry was coated onto a carbon-coated $\mathrm{Al}$ foil, dried at $80^{\circ} \mathrm{C}$ in vacuum overnight and punched into circular sheets, with diameters of $10 \mathrm{~mm}$ and loading mass of $\sim 1.5 \mathrm{mg} \mathrm{cm}^{-2}$. The glass fiber sheets of $16 \mathrm{~mm}$ in diameter were directly employed as separator and potassium metal foils served as counter electrodes in half-cells. $\mathrm{KPF}_{6}\left(1 \mathrm{~mol} \mathrm{~L}^{-1}\right)$ in $\mathrm{EC}+\mathrm{PC}$, DMC $+\mathrm{EC}, \mathrm{DME}+\mathrm{PC}(v / v=1: 1)$ were tested as electrolyte, among which $\mathrm{EC}+\mathrm{PC}$ turned out the most compatible one. Afterward, cells were constructed with EC+PC electrolyte. Galvanostatic charge-discharge (GCD) measurements were carried out on a battery test system (NEWARE CT-4008) using diverse voltage ranges and current densities. Cyclic voltammetry (CV) was performed on an Autolab (PGSTAT302N, Switzerland) electrochemical workstation. The full battery was assembled using KFOS cathode and SC as the anode, with the same separator and electrolyte as in half-cells. GCD was performed in a voltage range of $1.5-4.5 \mathrm{~V}$. The ca- pacity of the full cell was calculated based on the mass of active cathode material.

\section{Synchrotron-based X-ray measurements}

$\mathrm{X}$-ray absorption near-edge spectra (XANES) and extended X-ray absorption fine-structure (EXAFS) of Fe Kedge data of the samples were collected at SUT-NANOTEC-SLRI XAS beamline (BL5.2), Synchrotron Light Research Institute (SLRI), Thailand. A beam energy of 1.2 GeV generates the synchrotron radiation source at the storage ring and the beamline photon source covers an energy range of 40 to $1040 \mathrm{eV}$ at the resolving power of 10,000 . Typical loading of KFOS in each cathode was $5-8 \mathrm{mg} \mathrm{cm}^{-2}$.

\section{Theoretical calculations}

Computer simulations were performed with spin-polarized density functional theory as implemented in the Vienna $a b$ initio simulation package with projector-augmented-wave method. The plane-wave cutoff energy of $450 \mathrm{eV}$ was applied. The Perdew-Burke-Ernzerhof functional with the Hubbard $U$ correction 67 was adopted for the exchange correlation energy. An effective $U$ value of $4.0 \mathrm{eV}$ was applied to correct the onsite Coulomb repulsion of Fe $3 \mathrm{~d}$ electrons. The Brillouin zone was sampled with a $3 \times 4 \times 3 \Gamma$-centered $k$ mesh to keep the reciprocal spacing of all calculations with supercells of $\mathrm{K}_{16-x} \mathrm{Fe}_{12}\left(\mathrm{C}_{2} \mathrm{O}_{4}\right)_{12}\left(\mathrm{SO}_{4}\right)_{8}(16 \geq x \geq 4)$ less than $0.03 \AA^{-1}$ and the criteria for energy convergence was set to be $10^{-5} \mathrm{eV}$.

\section{RESULTS AND DISCUSSION}

The synthesized KFOS crystallites exhibit orange color and most of them are in the size of several millimeters (Fig. 1a). According to Sheltx refinement [33] on single crystal XRD data, it crystallizes in $P 2_{1} / c$ space group with $a=13.6775(7) \AA, b=5.4935(3) \AA, c=12.7483(6) \AA$, and $\beta=97.770(4)^{\circ}$. The crystallographic data and selected atom coordination are listed in Tables S1, S2. Interestingly, the structure exhibits a 2D framework consisting of puckered triple-layered $\mathrm{FeO}_{6}$ octahedra, which has not been reported before. $\mathrm{FeO}_{6}$ octahedra are connected by sulphate groups along $b$-axis and oxalate groups in $a c$ plane, and the triple-layer framework contains one layer of $\mathrm{Fe}\left(\mathrm{SO}_{4}\right)\left(\mathrm{C}_{2} \mathrm{O}_{4}\right)_{1 / 2}$, one layer of $\mathrm{Fe}\left(\mathrm{C}_{2} \mathrm{O}_{4}\right)$, and another layer of $\mathrm{Fe}\left(\mathrm{SO}_{4}\right)\left(\mathrm{C}_{2} \mathrm{O}_{4}\right)_{1 / 2}$, denoted as $\mathrm{L} 1, \mathrm{~L} 2$, and $\mathrm{L} 3$, respectively (Fig. 1b). L1 and L3 are identically $2 \mathrm{D}$, with $\mathrm{FeO}_{6}$ octahedra connected by $\mathrm{SO}_{4}$ along $c$-axis and by $\mathrm{C}_{2} \mathrm{O}_{4}$ along $b$-axis (Fig. S1a). Meanwhile, $\mathrm{L} 2$ is composed of $1 \mathrm{D} \mathrm{FeO}_{6}$ bridged by $\mathrm{C}_{2} \mathrm{O}_{4}$ along $b$-axis (Fig. $\mathrm{S} 1 \mathrm{~b}$ ). 
a

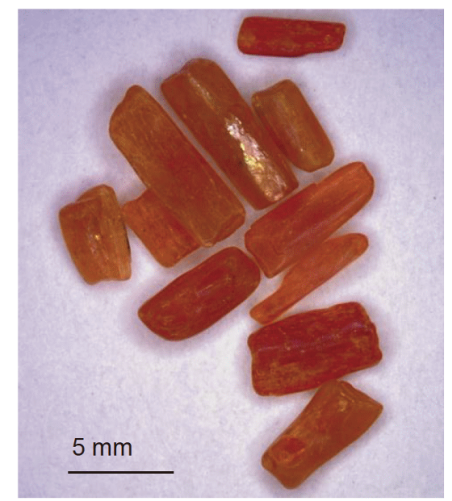

b

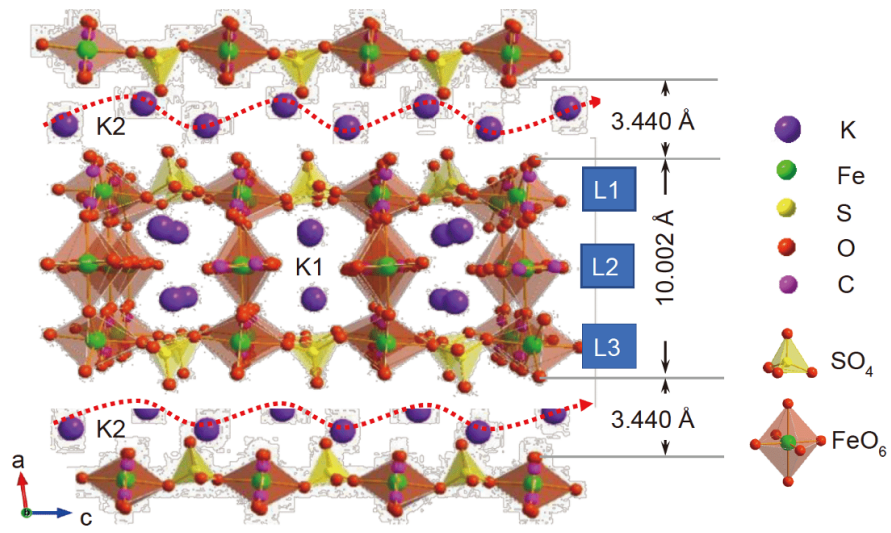

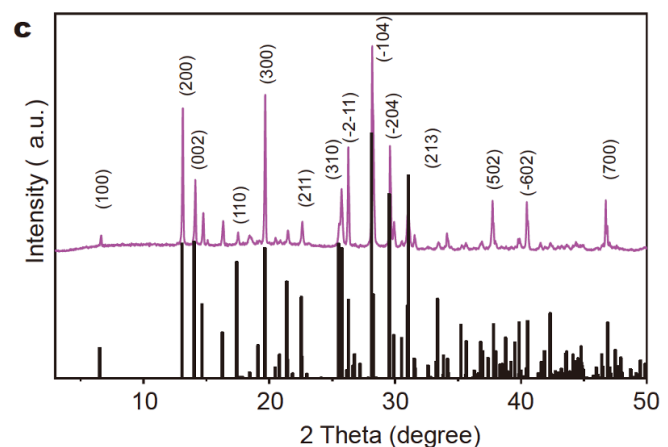

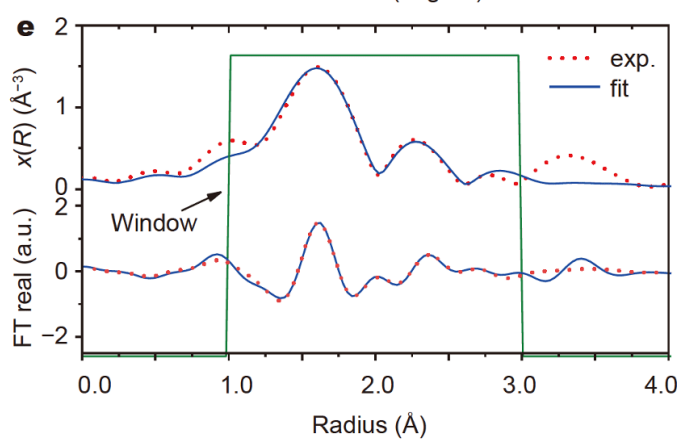

d
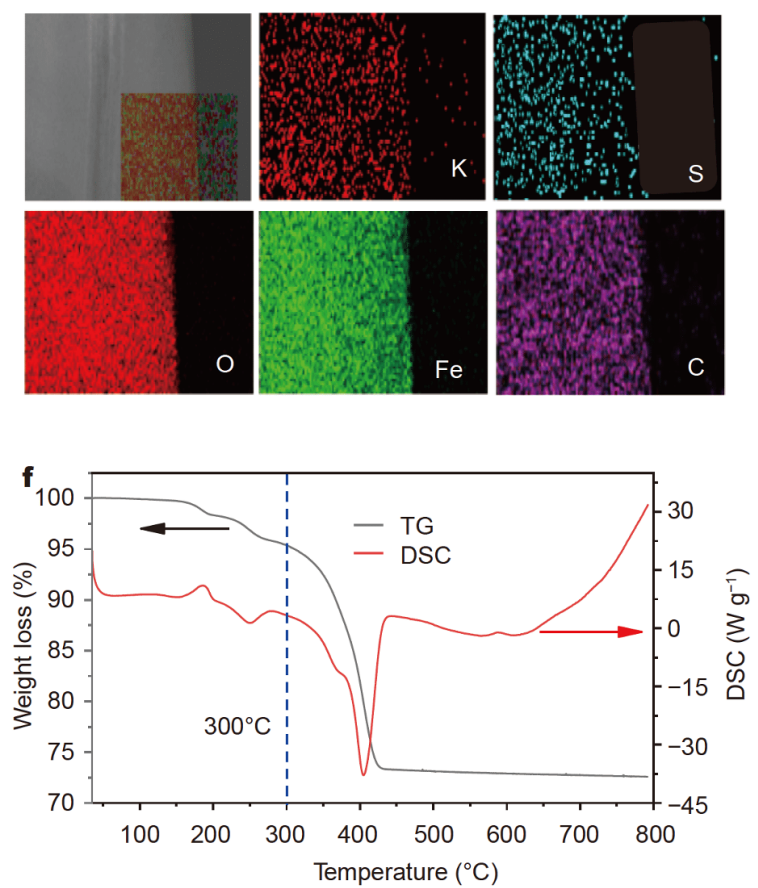

Figure 1 Characterizations of KFOS crystallites. (a) In-depth optical image. (b) Structure of the single crystal XRD. (c) Powder XRD. (d) TEM-EDS mapping of component elements. (e) Artemis fitting of Fe K edge EXAFS. (f) TG-DSC.

Two crystallographic iron sites are identified in KFOS: Fe1 in L1 and L3 is bonded to oxygen atoms of two bidentated oxalate groups and two edge-sharing sulphate groups, $\mathrm{Fe} 2$ in L2 shares oxygen with four oxalate groups (Fig. S2). The $\mathrm{K}$ cations are located half in cavities formed within triple layers (K1, between L1 and L2, or between L2 and L3) and half in interlayers (K2). Noticeably, the cavities of triple layers run along $b$ axis, with a crosssection of $4.576 \times 6.846 \AA$, obviously larger than the interstitial sites of 3.2 and $4.6 \AA$ in PBAs. Meanwhile, the interlayer distance is about $3.440 \AA$, at the same level as in layered oxide cathodes. Therefore, both K1 and K2 shall be movable in the framework. The detailed coordination and local environments of $\mathrm{Fe}$ and $\mathrm{K}$ ions are given in Figs S3, S4.

Powder XRD pattern of the hand-ground sample matches well with that deduced from the single crystal XRD (Fig. 1c and Fig. S5), confirming the phase and high purity of the synthesized KFOS. TEM image and the corresponding EDS mappings on a KFOS sheet prepared by focused ion beams demonstrate the even distribution of $\mathrm{K}, \mathrm{Fe}, \mathrm{S}, \mathrm{O}$, and $\mathrm{C}$ elements through the whole crystallite (Fig. 1d). As most polyanionic cathode materials containing $\mathrm{Fe}(\mathrm{II})$ are sensitive to air and moisture conditions $[29,30,34-36]$, a pristine sample was exposed in air for two weeks and then checked by synchrotron-based 
X-ray absorption spectroscopy (XAS). The fitting of Fe EXAFS by Artemis program [37] based on the structural model from single crystal XRD turns out quite well (Fig. 1e, Table S3), demonstrating KFOS can be stably stored in air. TG-DSC curves show the KFOS is stable until $300^{\circ} \mathrm{C}$ (Fig. 1f), then it starts to decompose into $\mathrm{Fe}_{2} \mathrm{O}_{3}$ and $\mathrm{K}_{2} \mathrm{SO}_{4}$, evidenced by XRD analysis on the residual powder (Fig. S6).

Motivated by the encouraging crystal structure of KFOS and its stability against air and heat, we evaluated its ability of $\mathrm{K}$-ion storage. Supposing the $\mathrm{Fe}^{2+} / \mathrm{Fe}^{3+}$ redox reaction dominates the electrochemical process, three quarter of potassium in KFOS shall be removable. In the first-principles simulations based on density functional theory (DFT) [38-40], the removal of corresponding Kions leads to a similar but contracted unit cell, with a slight volume change of $6.4 \%$, even smaller than that of LIB cathode $\mathrm{LiFePO}_{4}$ (7.8\%) (Fig. 2a, b) [41]. In terms of atomic structures, although all $\mathrm{Fe}-\mathrm{O}$ bonds experience a shrinkage upon depotassiation, with an average value of $9.3 \%$, the orientation of $\mathrm{FeO}_{6}$ octrhedra keeps almost unchanged, implying the stiffness of the framework (Fig. 2c). Besides, the calculated electronic density of states reveals that the top of the valence band consists predominantly of Fe 3d states in original KFOS (Fig. 2d). Upon depotassiation, the spin-up orbitals shift to deeper levels, while the spin-down orbitals move to higher levels above Fermi energy, allowing electron loss to its nearest anions. The simulations clearly illustrate that the extraction/(re)-insertion mechanism involves intrinsic $\mathrm{Fe}^{2+} / \mathrm{Fe}^{3+}$ redox, and indicate its high structural reversibility as a cathode for K-ion storage. Noteworthy, the capacity could be improved to $\sim 140 \mathrm{~mA} \mathrm{~h} \mathrm{~g}^{-1}$ if all $\mathrm{K}$-ions are moveable, with part of iron oxidized to $\mathrm{Fe}^{4+}$ or replaced with ions of multi-changeable electrons such as Mn.

Encouraged by the DFT calculations, electrochemical properties of KFOS were further investigated using prototype coin cells. Pristine KFOS was first ball-milled with conductive carbon to form a uniform mixture (Fig. S7), similar to other polyanionic electrode materials $[42,43]$. Galvanostatic cycling experiments were performed on half cells using a fixed rate of $100 \mathrm{~mA} \mathrm{~g}^{-1}$ to evaluate the best voltage window and the most compatible electrolyte. After examining several measurement conditions, 1.7-4.5 V and $1 \mathrm{~mol} \mathrm{~L}^{-1} \mathrm{KPF}_{6}$ in PC + EC $(1: 1 v / v)$ were verified be the optimal combination. The up threshold of
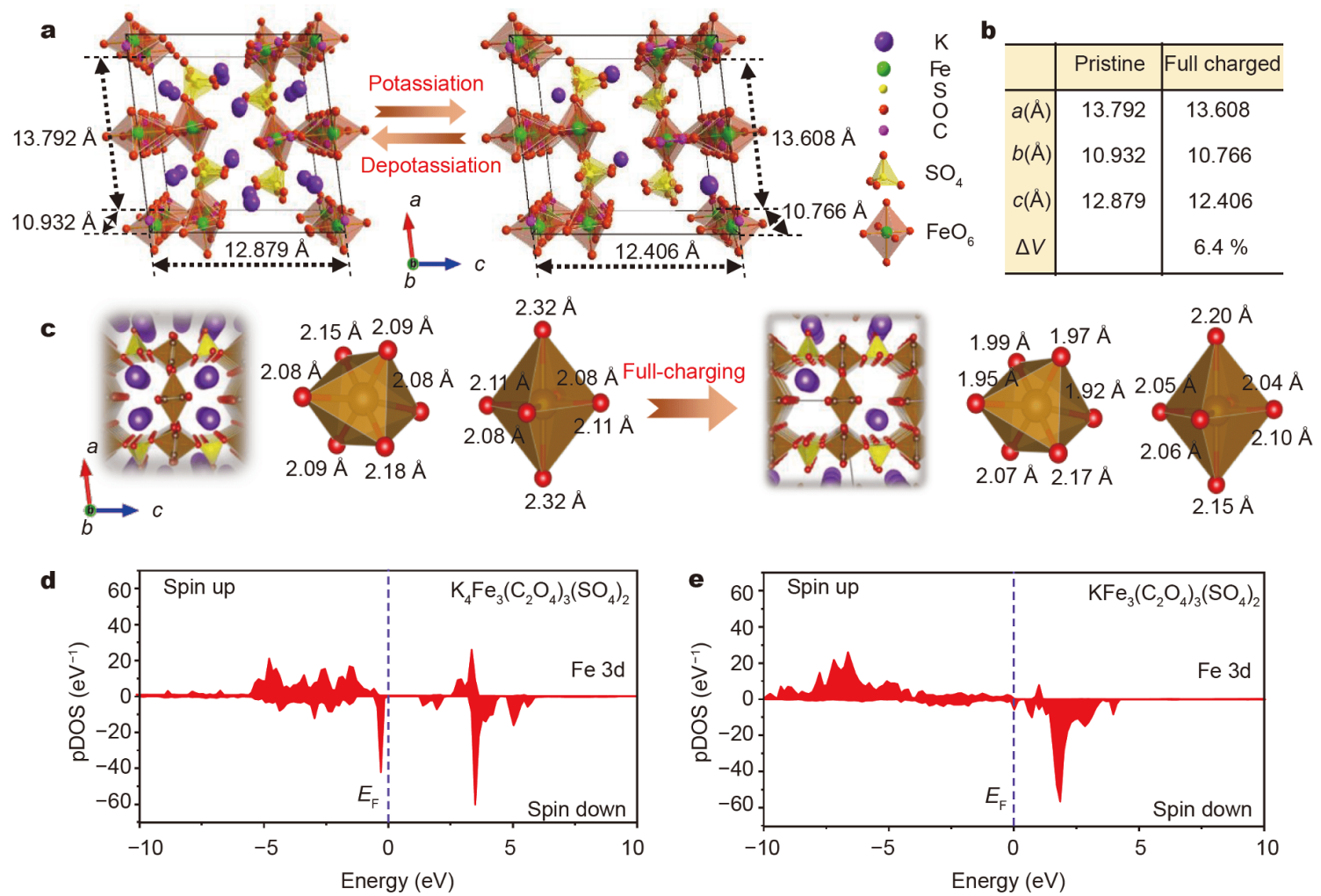

Figure 2 First principles calculations of KFOS. (a) Unit cell of potassiated and depotassiated KFOS, (b) the corresponding cell parameters and volume change, and (c) atomic structures of Fe environments. (d, e) Partial density of states projected onto the Fe $3 \mathrm{~d}$ orbitals. 
$4.5 \mathrm{~V}$ likely determined by carbonate electrolyte but not the KFOS, which restrained redox reactions and therefore limited the obtained capacity stated in detail below. Although the Coulombic efficiencies (CEs) were relatively low $(<85 \%)$ in the initial several cycles, possibly due to side reactions and activation process to form solid-electrolyte interface [44,45], it kept increasing as cycling proceeded and eventually stabilized at $>99 \%$. Other voltage windows and electrolytes either failed to allow sufficient $\mathrm{K}$-ion desertion/insertion or resulted in a rapid capacity decay or cell failure (Fig. S8). Following electrochemical studies of KFOS are therefore focused on the potential window of $1.7-4.5 \mathrm{~V}$ using $1 \mathrm{~mol} \mathrm{~L}^{-1} \mathrm{KPF}_{6}$ in PC + EC $(1: 1 v / v)$ as electrolyte.

Fig. 3a presents a typical stabilized GCD curve at a current density of $100 \mathrm{~mA} \mathrm{~g}^{-1}$. A discharge capacity of about $80 \mathrm{~mA} \mathrm{~h} \mathrm{~g}^{-1}$ was obtained. Although no clear plateaus can be observed, there is an obvious trend of flattening in the curve between 3.0 and $4.0 \mathrm{~V}$. CV curve shows that two main oxidation reactions occurred in the charging process, centered at 3.4 and $3.9 \mathrm{~V}$, respectively, while the corresponding reduction oxidation reactions exhibited a broad envelope between $3.0-3.7 \mathrm{~V}$ in the discharging process (Fig. $3 \mathrm{~b}$ ). The polarization of $0.3-0.4 \mathrm{~V}$ in KFOS cathode is relatively low compared with other KIB cathodes [24,46]. Reversible discharge capacities of around 85, 70, 64, 58 and $54 \mathrm{~mA} \mathrm{~h} \mathrm{~g}^{-1}$ were obtained at 100,200,300,400, and $500 \mathrm{~mA} \mathrm{~g}^{-1}$, respectively, and the polarization was almost unchanged with increasing current densities (Fig. 3c). Besides, the capacity could recover to its initial value as the current density increased-decreased over and over again, proving its great rate performance (Fig. 3d). The GCD curves at the $200^{\text {th }}$, $300^{\text {th }}, 400^{\text {th }}$ and $500^{\text {th }}$ cycles are well overlapped with decreasing polarization (Fig. 3e, Fig. S9). The medium discharged voltage of the KFOS was $2.9 \mathrm{~V}$ initially and got stable at $\sim 3.2 \mathrm{~V}$ with a persistent charging/discharging curve (Fig. $3 \mathrm{f}$ and inset). Moreover, a capacity of
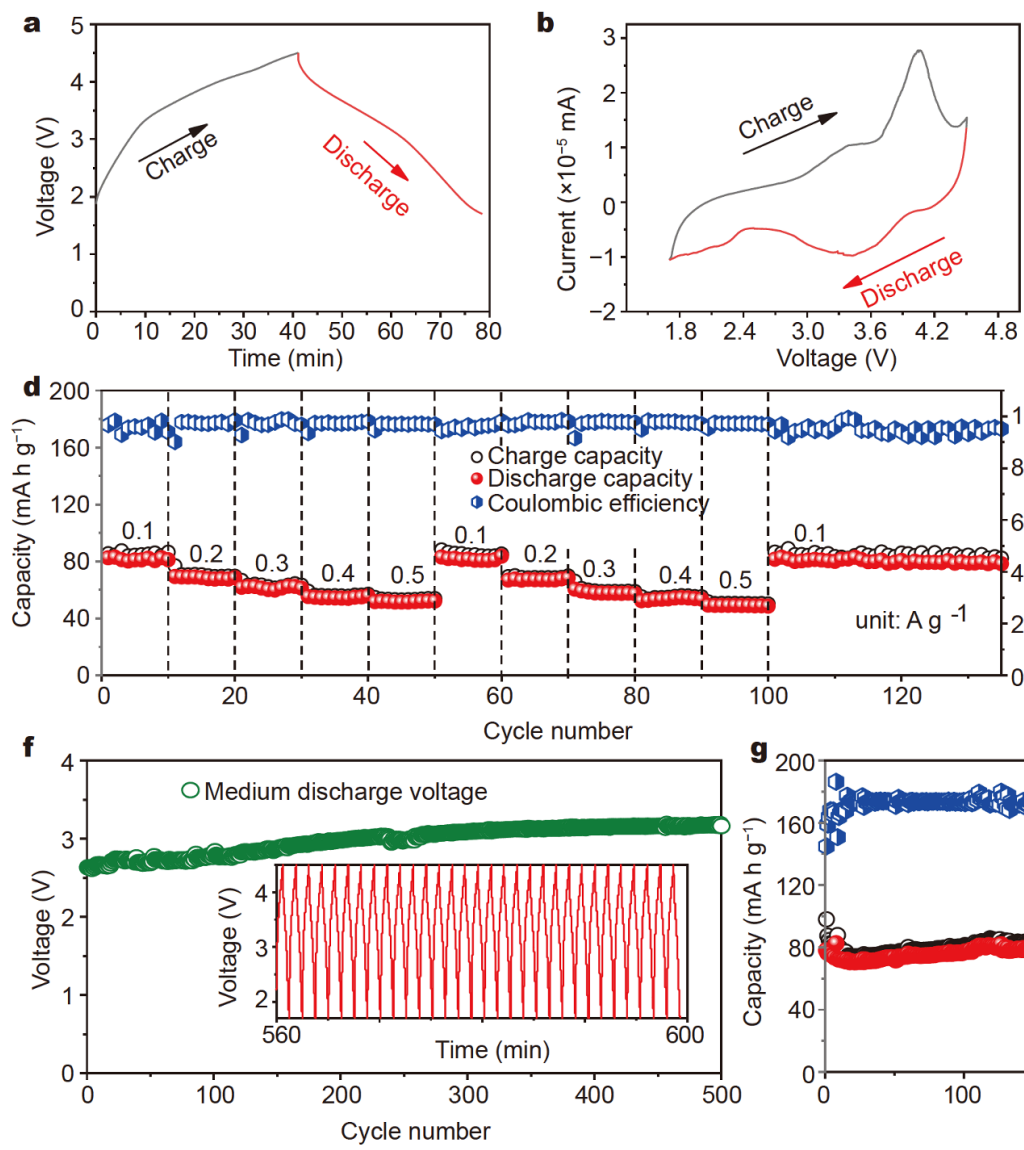

Voltage (V)
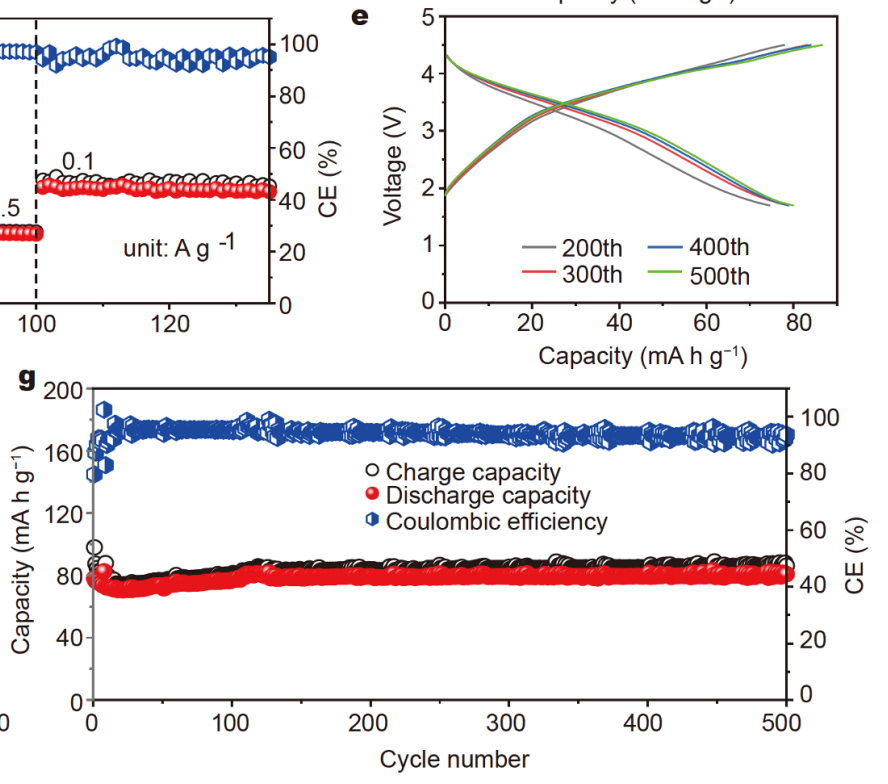

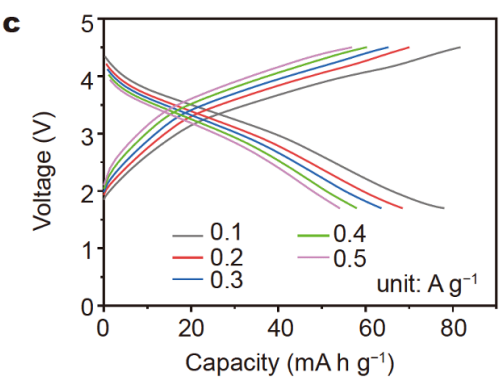

e

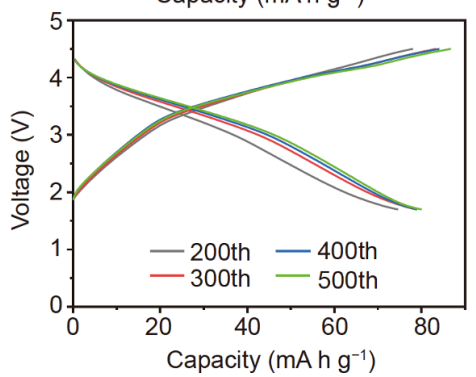

Figure 3 Electrochemical characterization of KFOS as the cathode in K-ion half cells. (a) Charge/discharge curve at the current density of $100 \mathrm{~mA} \mathrm{~g}^{-1}$. (b) CV curve. (c) Charge/discharge curves at varied current rates $\left(100,200,300,400\right.$ and $500 \mathrm{~mA} \mathrm{~g}^{-1}$ ), and (d) rate capacities. (e) Charge/discharge curves at $200^{\text {th }}, 300^{\text {th }}, 400^{\text {th }}$ and $500^{\text {th }}$ cycles of a cell at $100 \mathrm{~mA} \mathrm{~g}^{-1}$. (f) Progressive medium discharge voltages in cycling test. The inset shows the timevoltage curve of the last 40 cycles. $(\mathrm{g})$ Long-term cycling performance. 
$80 \mathrm{~mA} \mathrm{~h} \mathrm{~g}^{-1}$ was obtained after 500 cycles (Fig. 3g), demonstrating its impressive cycling stability. It should be noted that the capacity and stability of the KFOS cathode at $>4.5 \mathrm{~V}$ are still needed to be explored, waiting for further development of high-voltage electrolyte systems such as sulfone solvent, ionic liquids, etc.

To investigate the working mechanism of KFOS cathode for K-ion storage, we carried out synchrotron XAS of iron K-edge at different charging/discharging states to unveil the valance state and local environments of $\mathrm{Fe}$ during charge/discharge [47-49]. Fig. 4a shows the timeresolved XANES in one cycle. Upon charging, the edge gradually shifted to higher energies and reaches the maximum in fully charged sample, indicating the oxidation of $\mathrm{Fe}^{2+}$ to $\mathrm{Fe}^{3+}$. A reverse shift was obviously observed on discharged samples, and the XANES of samples at the initial and final states of one cycle matched well with each other, demonstrating the good reversibility of iron state during cycling (Fig. S10). The environments of $\mathrm{Fe}$ atoms at different states were further analyzed by $k^{2}$ -
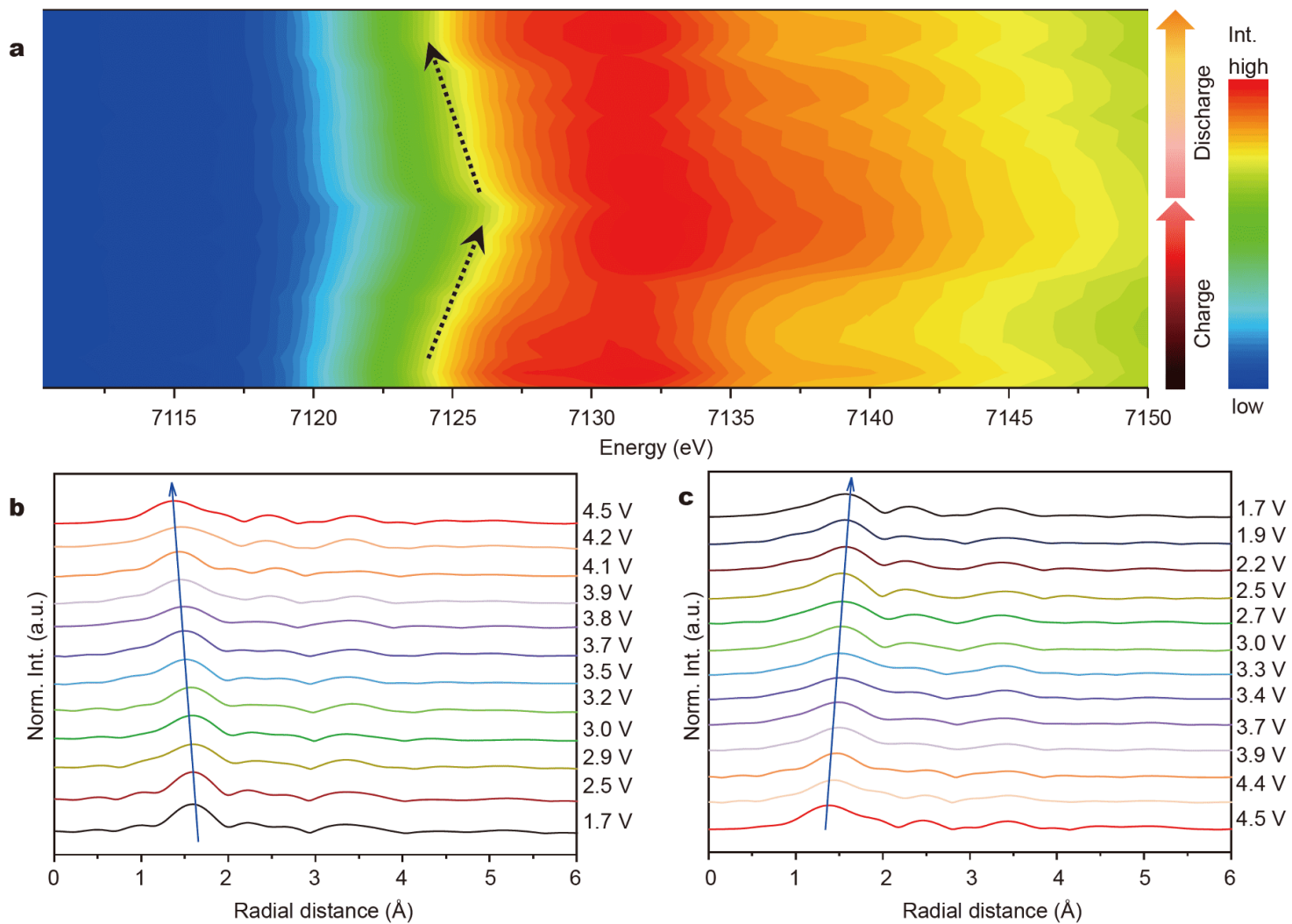

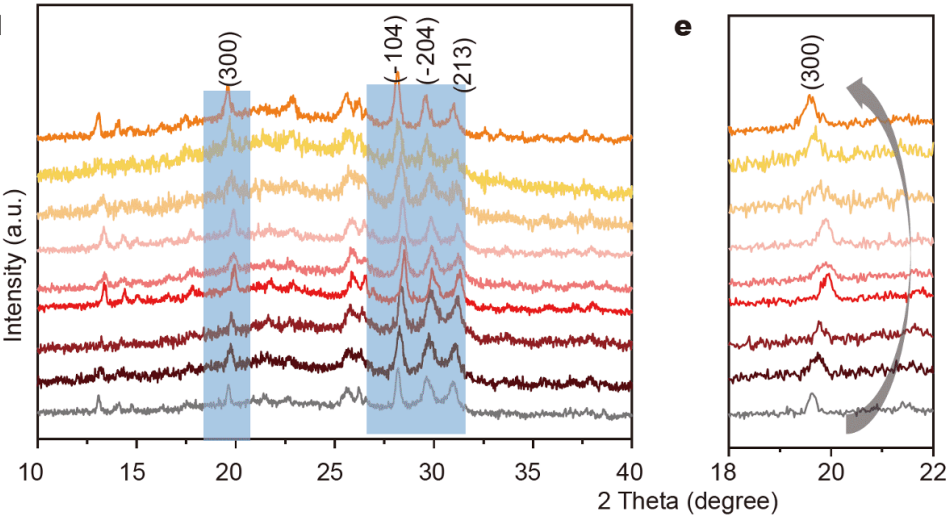

f

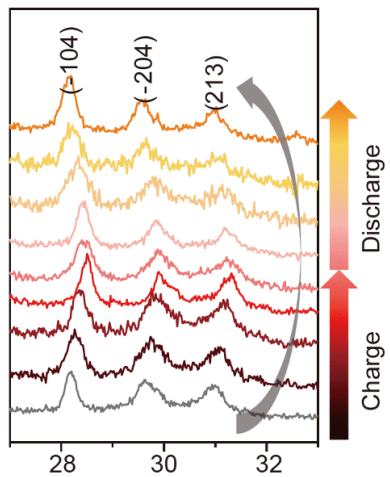

Figure 4 The working mechanism of KFOS in K-ion storage. (a) Mapping of Fe K edge XANES in a cycle. (b, c) EXAFS of Fe in charging and discharging. (d) Ex-situ XRD patterns in a cycle, and enlarged pattern in (e) $18^{\circ}-22^{\circ}$ and (f) $27^{\circ}-33^{\circ}$. 
weighted Fourier transform of EXAFS. The first peak within 1-2 $\AA$ range arose from the nearest $\mathrm{O}$ correlation, in accordance with KFOS crystal structure. As depicted in Fig. $4 \mathrm{~b}$, during the charging process, the first peak of EXAFS gradually moved to the lower radius, indicating the inter-atomic distance of $\mathrm{Fe}-\mathrm{O}$ was shortened. The sample at $4.5 \mathrm{~V}$ featured the shortest $\mathrm{Fe}-\mathrm{O}$ bond. While during the discharging, the first peak of EXAFS shifted to the longer radius (Fig. 4c), illustrating the $\mathrm{Fe}-\mathrm{O}$ bond was elongated progressively. The evolution of $\mathrm{Fe}-\mathrm{O}$ bond during the whole process is in accordance with the alteration of $\mathrm{Fe}^{2+} / \mathrm{Fe}^{3+}$, and the recovery of $\mathrm{Fe}-\mathrm{O}$ bond after cycling discloses the reversibility of the process.

Further, ex-situ XRD characterizations were performed on KFOS samples at different stages to detect its structural stability. Because of ball milling treatment of the pristine samples and grinding effect during the cell cycling process, recollected KFOS particles have been downsized to a great extent, resulting in the weakened and broadened XRD peaks (Fig. 4d). However, from the enlarged patterns at $18^{\circ}-22^{\circ}$ and $27^{\circ}-33^{\circ}$ (Fig. 4e-f), the diffraction peaks at $19.5^{\circ}, 28.2^{\circ}, 29.5^{\circ}$ and $31.0^{\circ}$, corresponding to (300), (104), (204) and (213) planes, respectively, migrated to larger degrees upon charging, and returned to original degrees on discharging. According to Bragg principles, it elucidates that the lattice of KFOS sample went through a contraction-expansion evolution during the charging/discharging process. Moreover, the similarity of whole XRD patterns and the recovery of the pattern after a cycle again verify the excellent structure stability of the KFOS cathode.

Our group has previously reported the synthesis and electrochemical study on $\mathrm{KFeC}_{2} \mathrm{O}_{4} \mathrm{~F}$ [24]. Compared with it, the current study exhibits following features: first, with the aim of using oxalate to obtain iron(II) compound in sulfate system, a mixed polyanionic compound was successfully obtained, which provids new synthesis routine in the preparation of iron(II) compound. Second, the structure of KFOS is distinctively $2 \mathrm{D}$, whereas the other are $3 \mathrm{D}$. Third, although the obtained capacity in this study is less than that in $\mathrm{KFeC}_{2} \mathrm{O}_{4} \mathrm{~F}$, considering the $\mathrm{K}$ rich nature of KFOS, it is possible to obtain an even higher capacity up to $\sim 140 \mathrm{~mA} \mathrm{~h} \mathrm{~g}^{-1}$ via strategies such as replacing iron with multi-valent ions such as $\mathrm{Mn}$ or $\mathrm{V}$ to allow multi electrons migration. Meanwhile, compared with the existing polyanionic KIBs cathodes, the cycling stability of KFOS is among the best (Table S4).

A proof-of-concept K-based full cell was further configured by paring this KFOS cathode with an SC anode. The characterization of SC (Fig. S11) confirmed the sample is as expected. Fig. 5a schematically illustrates its working mechanism. Upon charging, $\mathrm{K}$ ions are extracted from KFOS cathode and migrate into the SC anode, and a reverse process happens during discharging. Such a full cell at $4.5-\mathrm{V}$-charged state is capable of power more than ten LED bubbles (Fig. 5b). Fig. $5 c$ displays the performance of the full cell at different current densities. The capacity was fully rebounded when the current density
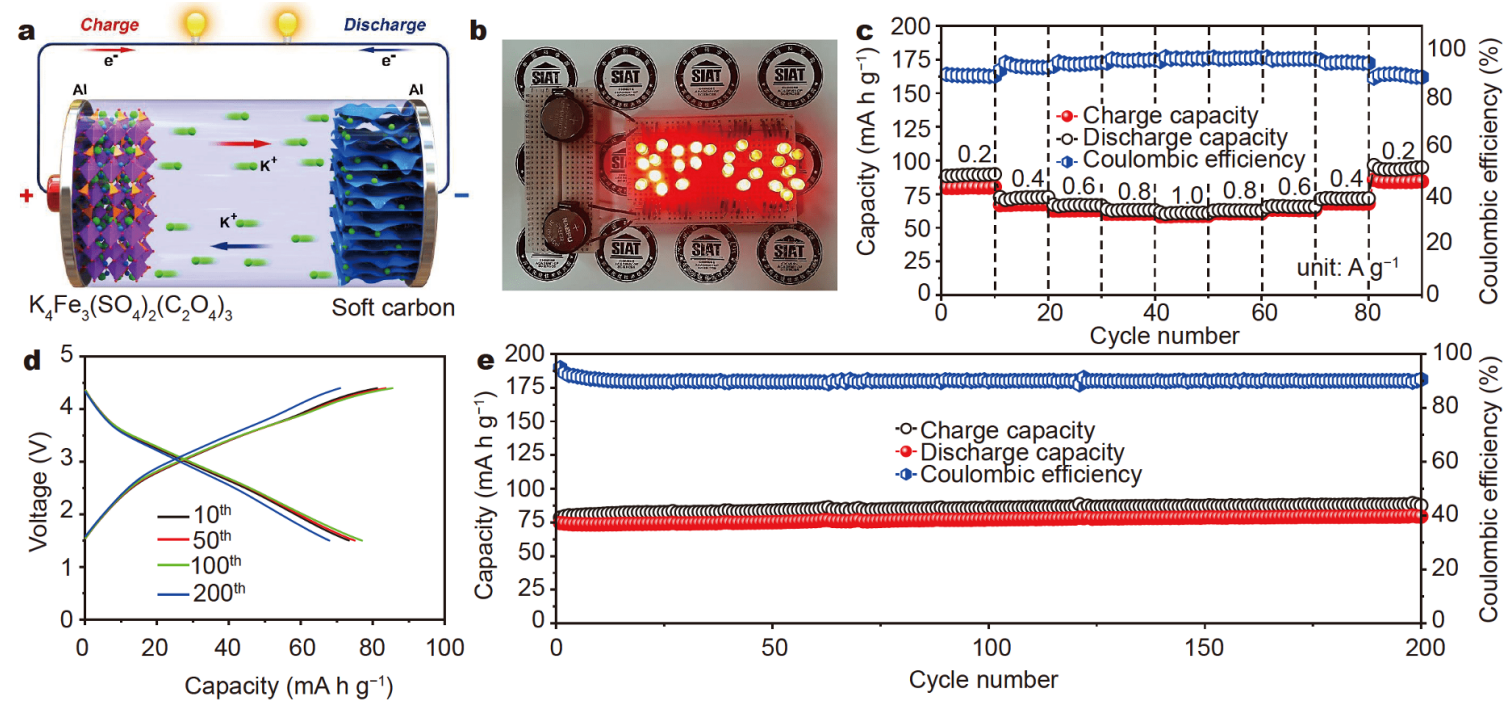

Figure 5 Full cell characterization. (a) Schematic illustration of the configuration and mechanism of the constructed K-ion full cell. (b) LED bulbs powered by two full cells. (c) Rate performance. (d) Charge/discharge curves at $10^{\text {th }}, 50^{\text {th }}, 100^{\text {th }}$ and $200^{\text {th }}$ cycles of a full cell at $200 \mathrm{~mA} \mathrm{~g}^{-1}$. (e) Longterm cycling performance. 
decreased to the initial $200 \mathrm{~mA} \mathrm{~g}^{-1}$, demonstrating the high stability of the cell at high rates. In addition, over $73 \%$ capacity was maintained when the current density increased from 200 to $1000 \mathrm{~mA} \mathrm{~g}^{-1}$, illustrating its excellent rate capability. Moreover, in the test of life span, the GCD curves of $10^{\text {th }}, 50^{\text {th }}, 100^{\text {th }}$ and $200^{\text {th }}$ cycles exhibited high resemblance and persistent polarization (Fig. 5d), and the cell was very stable after 200 cycles with a capacity retention close to $100 \%$ (Fig. 5e), indicating its promising potential for stable $\mathrm{K}$-ion storage in large-scale applications with low cost and environmental friendliness.

\section{CONCLUSIONS}

In summary, a new polyanionic compound KFOS was developed as a promising host for K-ion storage. Its unique crystal structure features a novel 2D triple-layered framework comprising wide interlayers and vast intralayer channels for $\mathrm{K}$ ion migration, which has never been reported previously. Benefiting from its reversible $\mathrm{Fe}^{2+} / \mathrm{Fe}^{3+}$ redox reactions and high structural stability, in our preliminary test, it delivers a reversible capacity of $85 \mathrm{~mA} \mathrm{~h} \mathrm{~g}^{-1}$ in $1.7-4.5 \mathrm{~V}$ with an average discharge voltage of around $3.2 \mathrm{~V}$ and $94 \%$ capacity retention after 500 cycles. Moreover, by coupling this cathode with SC anode, we successfully assembled a full K-ion cell with good rate performance and excellent cycling stability over 200 cycles, suggesting KFOS is a stable K-ion host. By further investigations using high-voltage electrolytes, optimization of its component and structure, for instance, replacing iron with multi-valent transition metals $\mathrm{Mn}$, a trace amount of doping, and surface modification to stabilize $\mathrm{Fe}^{4+}$, its capacity could be enhanced. Considering its advantages in easy preparation, rich resources, environmental friendliness, and excellent stability, the present study provides a feasible cathode for KIBs with the merits of low cost and environmental friendliness.

Received 15 July 2020; accepted 4 September 2020; published online 12 November 2020

1 Kong W, Yang W, Ning D, et al. Tuning anionic/cationic redox chemistry in a P2-type $\mathrm{Na}_{0.67} \mathrm{Mn}_{0.5} \mathrm{Fe}_{0.5} \mathrm{O}_{2}$ cathode material via a synergic strategy. Sci China Mater, 2020, 63: 1703-1718

2 Zhang W, Liu Y, Guo Z. Approaching high-performance potassium-ion batteries via advanced design strategies and engineering. Sci Adv, 2019, 5: eaav7412

3 Jia R, Jiang Y, Li R, et al. $\mathrm{Nb}_{2} \mathrm{O}_{5}$ nanotubes on carbon cloth for high performance sodium-ion capacitors. Sci China Mater, 2020, 63: 1171-1181

4 Chen $\mathrm{H}, \mathrm{Mu} \mathrm{Z}$, Li Y, et al. SnSe $\mathrm{e}_{2}$ nanocrystals coupled with hierarchical porous carbon microspheres for long-life sodium ion battery anode. Sci China Mater, 2020, 63: 483-491

5 Wang QC, Meng JK, Yue XY, et al. Tuning P2-structured cathode material by Na-site Mg substitution for Na-ion batteries. J Am Chem Soc, 2019, 141: 840-848

6 Yang W, Zhou J, Wang S, et al. Freestanding film made by necklace-like $\mathrm{N}$-doped hollow carbon with hierarchical pores for high-performance potassium-ion storage. Energy Environ Sci, 2019, 12: 1605-1612

7 Luo W, Li F, Zhang W, et al. Encapsulating segment-like antimony nanorod in hollow carbon tube as long-lifespan, high-rate anodes for rechargeable K-ion batteries. Nano Res, 2019, 12: 1025-1031

$8 \mathrm{Lu} \mathrm{Y}$, Chen J. Robust self-supported anode by integrating $\mathrm{Sb}_{2} \mathrm{~S}_{3}$ nanoparticles with $\mathrm{S}, \mathrm{N}$-codoped graphene to enhance $\mathrm{K}$-storage performance. Sci China Chem, 2017, 60: 1533-1539

9 Deng L, Yang Z, Tan L, et al. Investigation of the Prussian blue analog $\mathrm{Co}_{3}\left[\mathrm{Co}(\mathrm{CN})_{6}\right]_{2}$ as an anode material for nonaqueous potassium-ion batteries. Adv Mater, 2018, 30: 1802510

10 Di S, Ding P, Wang Y, et al. Interlayer-expanded $\mathrm{MoS}_{2}$ assemblies for enhanced electrochemical storage of potassium ions. Nano Res, 2020, 13: 225-230

11 Huang $\mathrm{H}, \mathrm{Xu} \mathrm{R}$, Feng Y, et al. Sodium/potassium-ion batteries: boosting the rate capability and cycle life by combining morphology, defect and structure engineering. Adv Mater, 2020, 32: 1904320

$12 \mathrm{Xu} \mathrm{Y,} \mathrm{Zhang} \mathrm{C,} \mathrm{Zhou} \mathrm{M,} \mathrm{et} \mathrm{al.} \mathrm{Highly} \mathrm{nitrogen} \mathrm{doped} \mathrm{carbon}$ nanofibers with superior rate capability and cyclability for potassium ion batteries. Nat Commun, 2018, 9: 1720

$13 \mathrm{Wu} \mathrm{Y,} \mathrm{Xu} \mathrm{Y,} \mathrm{Li} \mathrm{Y,} \mathrm{et} \mathrm{al.} \mathrm{Unexpected} \mathrm{intercalation-dominated}$ potassium storage in $\mathrm{WS}_{2}$ as a potassium-ion battery anode. Nano Res, 2019, 12: 2997-3002

14 Du X, Huang J, Guo X, et al. Preserved layered structure enables stable cyclic performance of $\mathrm{MoS}_{2}$ upon potassium insertion. Chem Mater, 2019, 31: 8801-8809

15 Han K, Meng J, Hong X, et al. Three-dimensional graphene-supported nickel disulfide nanoparticles promise stable and fast potassium storage. Nanoscale, 2020, 12: 8255-8261

16 Yi Z, Lin N, Zhang W, et al. Preparation of Sb nanoparticles in molten salt and their potassium storage performance and mechanism. Nanoscale, 2018, 10: 13236-13241

17 Tian Y, An Y, Wei H, et al. Micron-sized nanoporous vanadium pentoxide arrays for high-performance gel zinc-ion batteries and potassium batteries. Chem Mater, 2020, 32: 4054-4064

18 Chen J, Xiao Z, Meng J, et al. Novel layered $\mathrm{K}_{0.7} \mathrm{Mn}_{0.7} \mathrm{Ni}_{0.3} \mathrm{O}_{2}$ cathode material with enlarged diffusion channels for high energy density sodium-ion batteries. Sci China Mater, 2020, 63: 11631170

19 Wessells CD, Huggins RA, Cui Y. Copper hexacyanoferrate battery electrodes with long cycle life and high power. Nat Commun, 2011, 2: 550

20 Hu Y, Tang W, Yu Q, et al. Novel insoluble organic cathodes for advanced organic K-ion batteries. Adv Funct Mater, 2020, 30: 2000675

21 Kim H, Seo DH, Bianchini M, et al. A new strategy for highvoltage cathodes for $\mathrm{K}$-ion batteries: stoichiometric $\mathrm{KVPO}_{4} \mathrm{~F}$. Adv Energy Mater, 2018, 8: 1801591

22 Hameed AS, Katogi A, Kubota K, et al. A layered inorganicorganic open framework material as a $4 \mathrm{~V}$ positive electrode with high-rate performance for K-ion batteries. Adv Energy Mater, 2019, 9: 1902528

23 Yin X, Li H, Yuan R, et al. General formation of Prussian blue 
analogue microtubes for high-performance Na-ion hybrid supercapacitors. Sci China Mater, 2020, 63: 739-747

24 Ji B, Yao W, Zheng Y, et al. A fluoroxalate cathode material for potassium-ion batteries with ultra-long cyclability. Nat Commun, 2020, 11: 1225

25 Xue L, Li Y, Gao H, et al. Low-cost high-energy potassium cathode. J Am Chem Soc, 2017, 139: 2164-2167

26 Zhu YH, Yang X, Sun T, et al. Recent progresses and prospects of cathode materials for non-aqueous potassium-ion batteries. Electrochem Energ Rev, 2018, 1: 548-566

27 Yabuuchi N, Komaba S. Recent research progress on iron- and manganese-based positive electrode materials for rechargeable sodium batteries. Sci Tech Adv Mater, 2014, 15: 043501

28 Lan Y, Yao W, He X, et al. Mixed polyanionic compounds as positive electrodes for low-cost electrochemical energy storage. Angew Chem Int Ed, 2020, 59: 9255-9262

29 Lander L, Tarascon J-, Yamada A. Sulfate-based cathode materials for Li- and Na-ion batteries. Chem Rec, 2018, 18: 1394-1408

30 Chen $\mathrm{M}$, Cortie $\mathrm{D}, \mathrm{Hu} \mathrm{Z}$, et al. A novel graphene oxide wrapped $\mathrm{Na}_{2} \mathrm{Fe}_{2}\left(\mathrm{SO}_{4}\right)_{3} / \mathrm{C}$ cathode composite for long life and high energy density sodium-ion batteries. Adv Energy Mater, 2018, 8: 1800944

31 He H, Yao W, Tunmee S, et al. An iron-based polyanionic cathode for potassium storage with high capacity and excellent cycling stability. J Mater Chem A, 2020, 8: 9128-9136

32 Yao W, Armstrong AR, Zhou X, et al. An oxalate cathode for lithium ion batteries with combined cationic and polyanionic redox. Nat Commun, 2019, 10: 3483

33 Sheldrick GM. Crystal structure refinement with SHELXL. Acta Crystlogr C Struct Chem, 2015, 71: 3-8

34 Chen M, Hua W, Xiao J, et al. NASICON-type air-stable and allclimate cathode for sodium-ion batteries with low cost and highpower density. Nat Commun, 2019, 10: 1480

35 Lin B, Zhang S, Deng C. Understanding the effect of depressing surface moisture sensitivity on promoting sodium intercalation in coral-like $\mathrm{Na}_{3.12} \mathrm{Fe}_{2.44}\left(\mathrm{P}_{2} \mathrm{O}_{7}\right)_{2} / \mathrm{C}$ synthesized via a flash-combustion strategy. J Mater Chem A, 2016, 4: 2550-2559

36 Ha KH, Woo SH, Mok D, et al. $\mathrm{Na}_{4-\alpha} \mathrm{M}_{2+\alpha / 2}\left(\mathrm{P}_{2} \mathrm{O}_{7}\right)_{2}(2 / 3 \leq a \leq 7 / 8$, $\mathrm{M}=\mathrm{Fe}, \mathrm{Fe}_{0.5} \mathrm{Mn}_{0.5}, \mathrm{Mn}$ ): A promising sodium ion cathode for Naion batteries. Adv Energy Mater, 2013, 3: 770-776

37 Ravel B, Newville M. ATHENA , ARTEMIS , HEPHAESTUS : data analysis for X-ray absorption spectroscopy using IFEFFIT. J Synchrotron Rad, 2005, 12: 537-541

38 Kresse G, Hafner J. Ab initio molecular dynamics for liquid metals. Phys Rev B, 1993, 47: 558-561

39 Kresse G, Hafner J. Ab initio molecular-dynamics simulation of the liquid-metal-amorphous-semiconductor transition in germanium. Phys Rev B, 1994, 49: 14251-14269

40 Blöchl PE. Projector augmented-wave method. Phys Rev B, 1994, 50: $17953-17979$

41 Ouyang CY, Shi SQ, Fang Q, et al. $\mathrm{Li}_{1+x} \mathrm{FePO}_{4}(0 \leq x \leq 3)$ as anode material for lithium ion batteries: From ab initio studies. J Power Sources, 2008, 175: 891-896

42 Song T, Yao W, Kiadkhunthod P, et al. A low-cost and environmentally friendly mixed polyanionic cathode for sodium-ion storage. Angew Chem Int Ed, 2020, 59: 740-745

43 Barpanda P, Oyama G, Nishimura SI, et al. A 3.8-V earth-abundant sodium battery electrode. Nat Commun, 2014, 5: 4358

44 Manthiram A, Yu X, Wang S. Lithium battery chemistries enabled by solid-state electrolytes. Nat Rev Mater, 2017, 2: 16103

45 Bachman JC, Muy S, Grimaud A, et al. Inorganic solid-state electrolytes for lithium batteries: mechanisms and properties governing ion conduction. Chem Rev, 2016, 116: 140-162

46 Hosaka T, Shimamura T, Kubota K, et al. Polyanionic compounds for potassium-ion batteries. Chem Rec, 2019, 19: 735-745

47 Wang J, Tan S, Zhang G, et al. Fast and stable $\mathrm{Mg}^{2+}$ intercalation in a high voltage $\mathrm{NaV}_{2} \mathrm{O}_{2}\left(\mathrm{PO}_{4}\right)_{2} \mathrm{~F} / \mathrm{rGO}$ cathode material for magnesium-ion batteries. Sci China Mater, 2020, 63: 1651-1662

48 Kidkhunthod P. Structural studies of advanced functional materials by synchrotron-based X-ray absorption spectroscopy: BL5.2 at SLRI, Thailand. Adv Nat Sci-Nanosci Nanotechnol, 2017, 8: 035007

49 Liu D, Wu C, Chen S, et al. In situ trapped high-density single metal atoms within graphene: Iron-containing hybrids as representatives for efficient oxygen reduction. Nano Res, 2018, 11: $2217-2228$

Acknowledgements The authors acknowledge financial supports from the Key-Area Research and Development Program of Guangdong Province (2019B090914003), the National Natural Science Foundation of China (51822210, 51972329 and 51902339), Shenzhen Science and Technology Planning Project (JCYJ20190807172001755 and JCYJ20180507182512042), SIAT Innovation Program for Excellent Young Researchers (201811 and 201825), and the Science and Technology Planning Project of Guangdong Province (2019A1515110975 and 2019A1515011902).

Author contributions Yao $\mathrm{W}$ and Tang $\mathrm{Y}$ conceived and designed the study; Wang W performed the synthesis and electrochemical test; Ji B performed data analysis; Zhang X performed single crystal XRD; Ji B and Zheng Y performed the simulations; Zhou X, Kidkhunthod P and $\mathrm{He} \mathrm{H}$ contributed to the synchrotron-based tests. The manuscript was written through contributions of all authors. All authors have given approval to the final version of the manuscript.

Conflict of interest The authors declare that they have no conflict of interest.

Supplementary information Experimental details, cif file for KFOS, etc. are available in the online version of the paper.

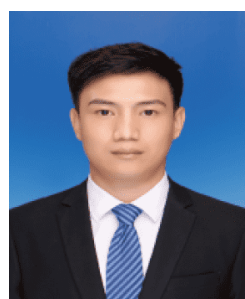

Weike Wang is a master of material engineering. His research focuses on the cathode materials for potassium ion batteries.

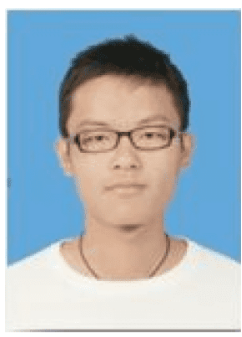

Bifa Ji is a doctoral candidate of physical chemistry. His research includes novel energy storage devices, first principle calculations, and energy conversion materials. 


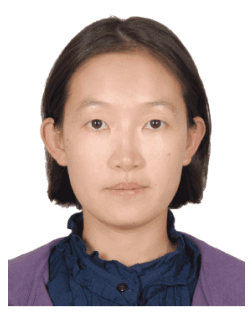

Wenjiao Yao is a doctor of inorganic chemistry. Her research interests cover crystallography, syntheses of novel compounds and their potential applications in batteries, magnetism, and optical fields.

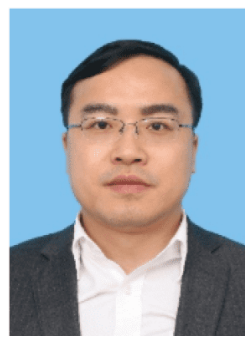

Yongbing Tang is a professor, and director of the Functional Thin Films Research Center, Shenzhen Institutes of Advanced Technology, Chinese Academy of Sciences. He has initiated the construction of new dual-ion battery systems based on the integrated design of alloy-type anode and current collector, and further developed other novel dual-ion battery systems based on other metal ions such as $\mathrm{Na}^{+}, \mathrm{K}^{+}, \mathrm{Ca}^{2+}$, and $\mathrm{Mg}^{2+}$, opening up a new way for the development of novel energy storage devices. His research interests cover novel energy storage devices and the key materials.
一种新型廉价、环境友好、结构稳定且具有大离 子通道的钾离子电池正极材料

王伟科 ${ }^{1,3 \dagger}$, 季必发 ${ }^{1,2 \dagger}$, 姚文娇 ${ }^{1 *}$, 张馨元 ${ }^{5}$, 郑勇平 ${ }^{1}$, 周小龙, Pinit Kidkhunthod ${ }^{6}$, 何海燕 ${ }^{1,3}$, 唐永炳 ${ }^{1,2,3,4^{*}}$

摘要 得益于钾的地壳丰度及其与锂的化学相似性, 钾离子电池有 望应用于大规模储能领域. 目前, 钾离子电池的性能尚不能满足实 用需求, 主要原因在于缺乏合适的正极材料. 基于硫酸根的强诱导 效应和草酸体系制备亚铁化合物的优势，本文制备了一种新型廉 价、环境友好且稳定的储钾正极材料 $\mathrm{K}_{4} \mathrm{Fe}_{3}\left(\mathrm{C}_{2} \mathrm{O}_{4}\right)_{3}\left(\mathrm{SO}_{4}\right)_{2}$. 其独特 的二维层状晶体结构具有 $3.379 \AA$ 的层间距, 且层内具有 $4.576 \times$ $6.846 \AA$ 的大环. 根据第一性原理计算, 该结构有利于钾离子的可逆 迁移, 且体积变化仅为 $6.4 \%$. 不同充放电态样品的同步辐射X射线 吸收光谱和XRD、半电池以及全电池的电化学表征证实了其优异 的电化学可逆性和结构稳定性. 通过成分调控、掺杂、结构优化 等策略, $\mathrm{K}_{4} \mathrm{Fe}_{3}\left(\mathrm{C}_{2} \mathrm{O}_{4}\right)_{3}\left(\mathrm{SO}_{4}\right)_{2}$ 正极材料的电化学性能有望进一步提 升. 因此, 本工作为廉价、环保的储钾正极材料提供了一种新的稳 定晶体模型. 